\title{
CFD-Based Study of Nozzle Section Geometry Effects on the Performance of an Annular Multi-Nozzle Jet Pump
}

\author{
Kai Xu ${ }^{1}$, Gang Wang ${ }^{2, *}$, Liquan Wang ${ }^{1}$, Feihong Yun ${ }^{1}$, Wenhao Sun ${ }^{1}$, Xiangyu Wang ${ }^{1}$ and \\ Xi Chen ${ }^{3,4}$ \\ 1 College of Mechanical and Electrical Engineering, Harbin Engineering University, Harbin 150001, China; \\ xukai0705@163.com (K.X.); wangliquan@hrbeu.edu.cn (L.W.); yunfeihong@hrbeu.edu.cn (F.Y.); \\ swh1053749521@163.com (W.S.); wangxiangyu325@126.com (X.W.) \\ 2 College of Shipbuilding Engineering, Harbin Engineering University, Harbin 150001, China \\ 3 College of Information and Communication Engineering, Harbin Engineering University, Harbin 150001, \\ China; chenxi_1113652@hrbeu.edu.cn \\ 4 College of Mechanical and Electrical Engineering, Heilongjiang Institute of Technology, Harbin 150050, China \\ * Correspondence: wanggang@hrbeu.edu.cn
}

Received: 13 December 2019; Accepted: 17 January 2020; Published: 21 January 2020

\begin{abstract}
CFD simulation and analysis of the internal flow field of the annular multi-nozzle jet pump are carried out to study the effects of nozzle section geometries on performance of the pump based on the finite volume method and realizable $k-\varepsilon$ model. The results show that the square nozzle peak efficiency is 3\% higher than that of the circular nozzle and $4.1 \%$ higher than that of the triangular nozzle. According to the simulation results, the mixing mechanism of the working fluid and second fluid is analyzed on the basis of the vortex dynamics. The results show the following: the recirculation area and the friction loss of the non-circular nozzle are reduced, and the mixing effect is improved; the streamwise vortex plays a major role in the mixing process and decays to an extremely small value at the end of the throat after attenuating rapidly in the suction chamber; compared with the streamwise vortex, the strength of the spanwise vortex is relatively stronger; the spanwise vortex still fluctuates after developing to a certain extent in the throat; the maximum streamwise vorticity peak value of the square nozzle is $31 \%$ more than that of the circular nozzle and $39 \%$ more than that of the triangular nozzle; the maximum spanwise vorticity peak value of the square nozzle is $19 \%$ less than that of the circular nozzle and $12 \%$ less than that of the triangular nozzle.
\end{abstract}

Keywords: annular multi-nozzle jet pump; numerical calculation; streamwise vortex; spanwise vortex

\section{Introduction}

The jet pump takes big advantages of having no moving parts, such as rotor and piston, which makes it particularly suitable for pumping mixed fluids containing large amounts of solid particles. Therefore, it has broad application prospects in engineering fields such as emergency draining, hydraulic dredging, and cooling of nuclear reactors [1-3]. Compared with the traditional central jet pump, the annular multi-nozzle jet pump can increase the interface surface area between the working fluid and the second fluid in the same conditions, thereby speeding up energy exchange, reducing the length of the throat and the size of the pump, and improving the pump efficiency.

In recent years, computational fluid dynamics (CFD) and experimental methods have been used to study the effects of geometric structures on the performance of jet pumps. Yang and Long [4] studied the mixing process of annular nozzles with different structures by using CFD techniques. The entrainment rate (ER) and critical back pressure (CBP) of the jet pump were improved by using nozzles with 
special shapes. Deng [5] combined the self-oscillating suction chamber with a conventional annular jet pump, and the numerical results showed that the efficiency was increased by $10 \%$. Sheha [6] investigated the effect of the diffuser angle on the performance of the central jet pump and found that the optimum angle for diffuser with the maximum efficiency was $5^{\circ}$. Sun [7] presented the flow field inside the jet pump to clarify the effect of inlet convergence angles on pump efficiency and suction performance. The simulation results show that the pump efficiency and suction performance decreases gradually with the increase of inlet convergence angle. Fan [8] created surrogate models of the pump's behavior using the moving least-squares method based on the high fidelity CFD solutions and carried out the global optimization using the surrogates. The optimization results showed that the efficiency of the pump was increased by $13.8 \%$. Zou [9] carried out numerical study in order to show the effect of horizontal installation and the vertical installation of the performance of jet pump. They concluded that the vertical inlet produced the higher efficiency. Zhu [10] proposed jet pump without the throat and made use of the unavoidable turbulent flow in the diffuser to induce cavitation. The proposed structure significantly enhanced cavitating pump operating range and operation ability. Lyu [11] conducted structural optimization studies on the annular jet pump through the design of experiments (DOE) method together with CFD. The results showed that the throat length, diffusion angle and suction chamber angle are the most critical parameters that determine the performance of the central jet pump. Duan [12] studied the effect of various structural parameters on the performance of the annular multi-nozzle jet pump through a large number of experiments, which provided a theoretical basis for the rational design of the pump. Based on the theory of vortex dynamics, Long [13] studied the influence of the number and distribution of nozzles on the internal flow field and performance through numerical simulation. The results showed that the arrangement of nozzles should be distributed along the circumference. Yang [14] studied the effects of different turbulence models and wall boundary treatment methods on internal flow field simulation results and found that the Realizable $k-\varepsilon$ model could obtain more accurate performance prediction and internal flow field details. Long [15] numerically investigated the effects of the nozzle exit tip thickness on the performance and the flow field of a jet pump. According to their results, the thickness only slightly affected the pressure ratio and efficiency of the pump, whereas its effect on the flow field is relatively big. Yamazaki [16] compared the effects of the notched nozzle, the flow-shaped nozzle and the conventional circular nozzle on the internal mixing process and performance of the jet pump. Guillaume [17] compared the jet pump efficiencies of the elliptical nozzle and the circular nozzle and found that the efficiency of the elliptical nozzle was approximately six times more than that of the circular at high flow rate. Mallerla [18] improved the efficiency of the jet pump by optimizing the shape of the outer wall surface of the central jet pump nozzle. Kwon [19] studied the effect of the suction pipe angle on the performance of central jet pump by numerical method. Tadashi [20] conducted numerical simulation and experimental researches on the central multi-nozzle jet pump and analyzed the internal flow field and efficiency characteristics of the jet pump, as well as the influence of wall roughness.

However, most of the current researches focus on the central jet pump and annular jet pump. The researches on the annular multi-nozzle jet pump are not sufficient, especially regarding the application of the non-circular nozzle. Compared with the conventional circular nozzle, the non-circular nozzle can further improve the contact area between the working fluid and the secondary fluid resulting in different jet characteristics. Therefore, this paper firstly simulates the internal flow field of multi-nozzle annular jet pumps with different nozzle section shapes, comparing the effects of nozzle section shapes on the performance and flow field. Based on the theory of vortex dynamics, the mixing mechanism of the annular multi-nozzle jet pump and the influence of vortex structure on its performance and flow field are studied, providing a theoretical basis for the practical application of annular multi-nozzle jet pumps. 


\section{Structure and Principle of an Annular Multi-Nozzle Jet Pump}

The structure of an annular multi-nozzle jet pump is as shown in Figure 1. The working fluid from the pressure source is driven through the nozzles with a high speed and forms a vacuum in the downstream suction chamber. The secondary fluid is sucked up and flows through the throat together with the high-velocity working fluid. The working fluid transfers a part of the energy to the secondary fluid. In this way, the working fluid is slowed down, and the secondary fluid is accelerated. The velocities of the two fluids reach the same level at the end of the throat, and the mixing process is completed. In the diffuser, the flow rate gradually decreases and the pressure rises up to the ambient pressure and the mixed fluid is discharged out of the diffuser.

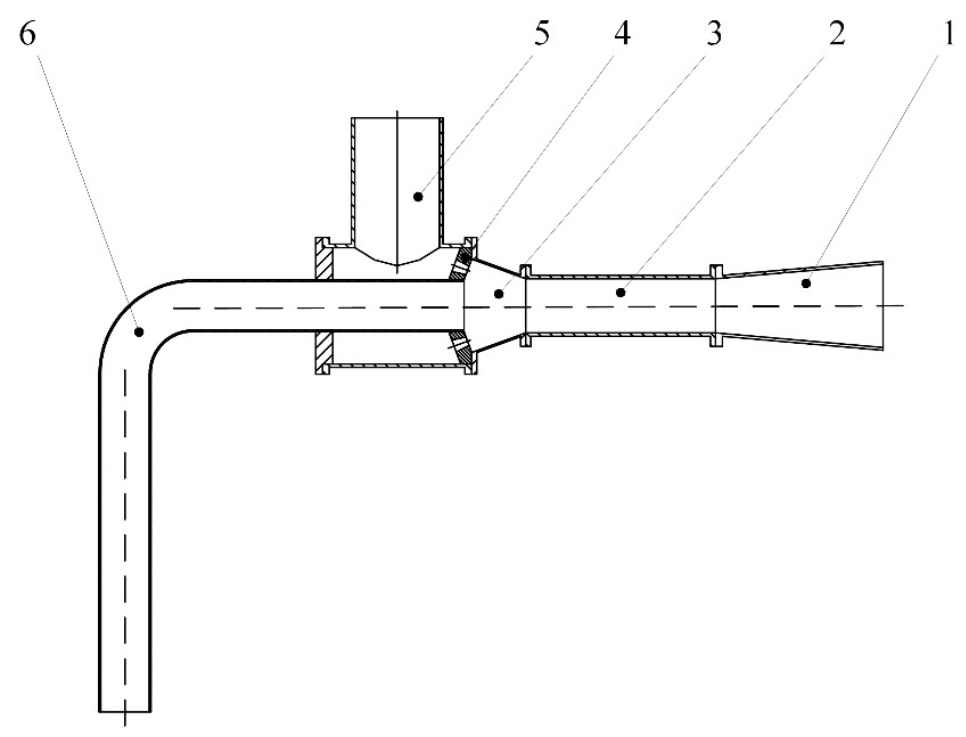

Figure 1. Structure of the annular multi-nozzle jet pump. 1: Diffuser; 2: Throat 3: Suction chamber 4: Annular multi-nozzle 5: Working fluid inlet 6: Suction pipe.

The performance of the jet pump depends on the turbulent mixing effect of the working fluid and the secondary fluid. The flow of the jet pump is a confined space jet and the performance relies on the structure design of the jet pump. The working fluid of the annular multi-nozzle jet pump produces multiple jets and the total area of the interface of the two fluids is much higher than that of the central jet pump. The fluids can exchange energy and momentum relatively quicker in a short throat and thereby reduces the friction loss in the throat to improve the pump efficiency.

The dimensionless pressure ratio $h$ and efficiency $\eta$ are used to investigate the performance of the pump. The definitions are as follows:

$$
\begin{gathered}
h=\frac{\Delta p_{o}}{\Delta p_{w}}=\frac{\left(p_{o}+\gamma_{o} \frac{V_{o}^{2}}{2 g}+\gamma_{o} z_{o}\right)-\left(p_{s}+\gamma_{s} \frac{V_{s}^{2}}{2 g}+\gamma_{s} z_{s}\right)}{\left(p_{w}+\gamma_{w} \frac{V_{w}^{2}}{2 g}+\gamma_{w} z_{w}\right)-\left(p_{o}+\gamma_{o} \frac{V_{o}^{2}}{2 g}+\gamma_{o} z_{o}\right)^{\prime}} \\
\eta=\frac{Q_{s}}{Q_{w}} \cdot \frac{\Delta p_{o}}{\Delta p_{w}-\Delta p_{o}}=q \frac{h}{1-h^{\prime}}
\end{gathered}
$$

where,

$$
q=\frac{Q_{s}}{Q_{w}}
$$

In these equations, $q$ is the flow ratio, $p$ is the static pressure, $Q$ is the volume flow rate, $\gamma$ is the unit weight, $g$ is the gravitational acceleration, $z$ is the water head, $V$ is the sectional average velocity, 
footnotes $w, s$ and $o$ represent the working fluid at the inlet, secondary fluid at the inlet and their mixture at the outlet respectively.

\section{CFD Modeling}

CFD simulation is used to investigate the performance of the annular multi-nozzle pumps with three nozzle section geometries, circular, square and triangle.

\subsection{Geometry Model}

Based on the research [12], the number of jet pump nozzles designed in this paper is 6, and the geometry model is as shown in Figure 2. The cross-section of every part of the fluid domain except the multi-nozzle is circular, and the dimensions are listed in Table 1.

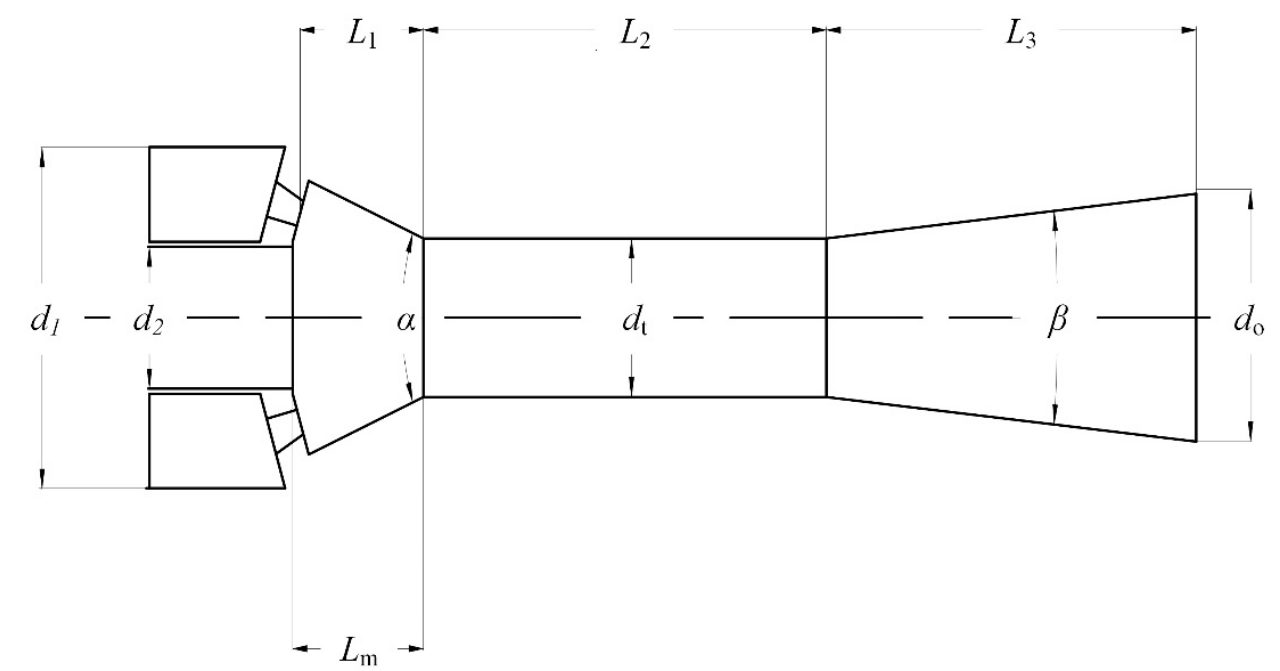

Figure 2. The geometry model of the annular multi-nozzle jet pump.

Table 1. The dimensions of the geometry model.

\begin{tabular}{ccccccccccc}
\hline$d_{1}$ & $\boldsymbol{d}_{\mathbf{2}}$ & $\boldsymbol{d}_{\mathbf{t}}$ & $\boldsymbol{d}_{\mathbf{0}}$ & $\boldsymbol{L}_{\mathrm{m}}$ & $\boldsymbol{L}_{\mathbf{1}}$ & $\boldsymbol{L}_{\mathbf{2}}$ & $\boldsymbol{L}_{\mathbf{3}}$ & $\boldsymbol{R}$ & $\boldsymbol{\alpha}$ & $\boldsymbol{\beta}$ \\
\hline $0.344 \mathrm{~m}$ & $0.143 \mathrm{~m}$ & $0.16 \mathrm{~m}$ & $0.25 \mathrm{~m}$ & $0.2 \mathrm{~m}$ & $0.18 \mathrm{~m}$ & $0.56 \mathrm{~m}$ & $0.514 \mathrm{~m}$ & $0.12 \mathrm{~m}$ & $30^{\circ}$ & $10^{\circ}$ \\
\hline
\end{tabular}

The nozzles with square, circular and triangular sections were designed, as shown in Figure 3. The section areas are the same for the three models. The ratio of the throat cross-sectional area to the nozzle outlet area is 6.25 .

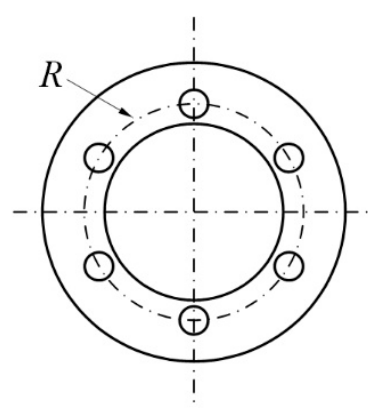

(a)

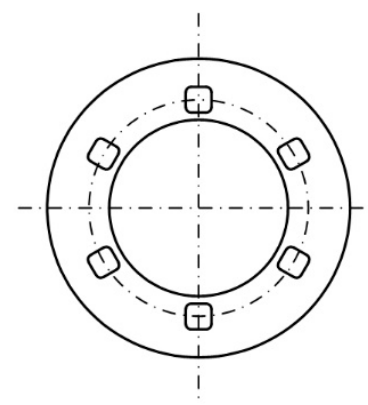

(b)

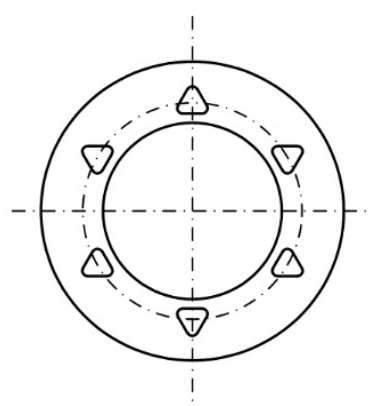

(c)

Figure 3. The nozzle structures. (a) Circular nozzle; (b) Square nozzle; (c) Triangle nozzle. 


\subsection{CFD Simulation}

The following assumptions are used in the simulation:

(1) The flow of the jet pump is steady and the medium is incompressible;

(2) The heat transfer between water and surroundings does not occur;

(3) The surface roughness is taken as zero;

(4) The effect of buoyancy is negligible.

Based on these assumptions, the continuity and momentum equations can be written as

$$
\begin{gathered}
\frac{\partial(\rho \gamma)}{\partial x_{i}}=0, \\
\frac{\partial\left(\rho u_{j} u_{i}\right)}{\partial x_{j}}=\frac{\partial}{\partial x_{j}}\left[\mu \frac{\partial u_{i}}{\partial x_{j}}-\rho \overline{u_{i} u_{j}}\right]-\frac{\partial p}{\partial x_{i}},
\end{gathered}
$$

where Reynolds stresses are

$$
-\rho \overline{u_{i} u_{j}}=\mu_{t}\left[\frac{\partial u_{i}}{\partial x_{j}}+\frac{\partial u_{j}}{\partial x_{i}}\right]-\frac{2}{3} \rho k \delta_{i j} .
$$

In these equations, $u_{i}$ is the velocity component, $x_{i}$ is the space coordinate, $\delta$ is the boundary layer thickness, $\mu$ is the dynamic viscosity, $\mu_{t}$ is the turbulent viscosity, and $k$ is the turbulent dynamic energy.

The internal flow of the jet pump belongs to turbulent flow, and there is a complex mixing shear layer between the working fluid and the secondary fluid. Therefore, it is necessary to select a suitable turbulence model to ensure the simulation accuracy. In addition, the simulation of the near-wall region requires an appropriate wall treatment to accurately reflect the influence of the wall on the flow field. Realizable $k-\varepsilon$ model and standard wall function can obtain accurate performance prediction and internal flow field [14].

The Realizable $k-\varepsilon$ model proposed by Shih [21] differs from the standard $k-\varepsilon$ model in two ways: The realizable $k-\varepsilon$ model contains an alternative equation for the turbulent viscosity; A modified transport equation for the dissipation rate, $\varepsilon$, has been derived from an exact equation for the transport of the mean-square vorticity fluctuation. This modified transport equation has shown substantial improvements over the standard $k-\varepsilon$ model where the flow features include strong streamline curvature, vortices, and rotation. The term "realizable" means that the model satisfies certain mathematical constraints on the Reynolds stresses, consistent with the physics of turbulent flows. The modeled transport equations for $k$ and $\varepsilon$ in the realizable $k-\varepsilon$ model are:

$$
\begin{aligned}
& \frac{\partial(\rho k)}{\partial t}+\frac{\partial\left(\rho k u_{j}\right)}{\partial x_{j}}=\frac{\partial}{\partial x_{j}}\left[\left(\mu+\frac{\partial u_{i}}{\sigma_{k}}\right) \frac{\partial(k)}{\partial x_{j}}\right] \\
& +G_{k}+G_{b}-\rho \varepsilon-Y_{M}+S_{k} \\
& \frac{\partial(\rho \varepsilon)}{\partial t}+\frac{\partial\left(\rho \varepsilon u_{j}\right)}{\partial x_{j}}=\frac{\partial}{\partial x_{j}}\left[\left(\mu+\frac{\partial u_{t}}{\sigma_{\varepsilon}}\right) \frac{\partial \varepsilon}{\partial x_{j}}\right]+\rho C_{1} S \varepsilon \\
& -\rho C_{2} \frac{\varepsilon^{2}}{k+\sqrt{v \varepsilon}}+C_{1 \varepsilon} \frac{\varepsilon}{k} C_{3 \varepsilon} G_{b}+S_{\varepsilon}
\end{aligned}
$$

where,

$$
C_{1}=\max \left[0.43, \frac{\eta}{\eta+5}\right], \eta=S \frac{k}{\varepsilon}, S=\sqrt{2 S_{i j} S_{i j}},
$$

In these equations, $S$ is the strain rate magnitude, $G_{k}$ represents the generation of turbulence kinetic energy due to the mean velocity gradients. $G_{b}$ is the generation of turbulence kinetic energy due to buoyancy. $Y_{m}$ represents the contribution of the fluctuating dilatation in compressible turbulence to the overall dissipation rate. $C_{2}$ and $C_{\varepsilon}$ are constants. $\sigma_{k}$ and $\sigma_{k}$ are the turbulent Prandtl numbers for $k$ and $\varepsilon$, respectively. $S_{k}$ and $S_{\varepsilon}$ are user-defined source terms. 
As in other $k-\varepsilon$ models, the eddy viscosity is computed from:

$$
\mu_{t}=\rho C_{\mu} \frac{k^{2}}{\varepsilon},
$$

The difference between the realizable $k-\varepsilon$ model and the standard model is that $C_{\mu}$ is no longer constant. It is computed from

$$
C_{\mu}=\frac{1}{A_{0}+A_{S} \frac{k U^{*}}{\varepsilon}},
$$

where

$$
\begin{aligned}
& U^{*} \equiv \sqrt{S_{i j} S_{i j}+\widetilde{\Omega}_{i j} \widetilde{\Omega}_{i j}} \\
& \widetilde{\Omega}_{i j}=\Omega_{i j}-2 \varepsilon_{i j k} \omega_{k} \\
& \Omega_{i j}=\bar{\Omega}_{i j}-\varepsilon_{i j k} \omega_{k} \\
& A_{0}=4.04, A_{s}=\sqrt{6} \cos \varphi \\
& \varphi=\frac{1}{3} \cos ^{-1}(\sqrt{6} W), W=\frac{S_{i j} S_{j k} S_{k i}}{\widetilde{S}^{3}}, \widetilde{S}=\sqrt{S_{i j} S_{i j}}, S_{i j}=\frac{1}{2}\left(\frac{\partial u_{j}}{\partial x_{i}}+\frac{\partial u_{i}}{\partial x_{j}}\right),
\end{aligned}
$$

where $\bar{\Omega}_{i j}$ is the mean rate-of-rotation tensor. It can be seen that $C_{\mu}$ is a function of the mean strain and rotation rates, the angular velocity of the system rotation, and the turbulence fields $(k$ and $\varepsilon$ ). In Equation (11), $C_{\mu}$ can recover the standard value of 0.09 for an inertial sublayer in an equilibrium boundary layer.

ANSYS Fluent 18.2 provides a scalable wall function instead of the standard wall function. Based on the standard wall function, the scalable wall function introduces a limit function in the $y^{*}$ calculation:

$$
\widetilde{y}^{*}=\operatorname{MAX}\left(y^{*}, y^{*} \text { limit }\right),
$$

where the value of $y^{*}$ limit is 11.5 .

Scalable wall functions avoid the deterioration of standard wall functions under grid refinement below $y^{*}<11$. These wall functions produce consistent results for grids of arbitrary refinement. For coarser grids with $y^{*}>11$, the standard wall functions are identical. Therefore, this paper used the scalable wall function instead of the standard wall function.

In this paper, both the working fluid and the secondary fluid are water. The hexahedral element is used and grid is created by ICEM CFD. Velocity inlet is used for the working fluid and the secondary fluid inlets. Outflow is set as the diffuser outlet. The second order upwind scheme is adopted for spatial discretization of the convection terms. The pressure-based solver is used in the simulation, and the SIMPLE algorithm is used to couple the pressure and velocity.

\subsection{Comparison with Experiments}

Duan [12] has obtained the efficiency curve of a six-nozzle annular jet pump with different flow ratios through experiments. The ratio of the throat cross-sectional area to the nozzle outlet area was 18 . In this paper, the numerical simulation was carried out under the same conditions as the experiment and compared with the experimental results, listed in Table 2. The maximum error was $\pm 7.89 \%$. Therefore, the results calculated by the simulation scheme agree well with the experiment data and the simulation scheme can be utilized in the further investigation. 
Table 2. Comparison of the experimental and simulation data.

\begin{tabular}{cccc}
\hline $\boldsymbol{q}$ & $\boldsymbol{h}$ (Experimental Data) & $\boldsymbol{h}$ (Simulation Data) & Error (\%) \\
\hline 0.01 & 0.0811 & 0.0827 & \pm 1.97 \\
0.25 & 0.0807 & 0.0819 & \pm 1.49 \\
0.50 & 0.0804 & 0.0800 & \pm 0.50 \\
0.75 & 0.0797 & 0.0775 & \pm 2.76 \\
1.00 & 0.0778 & 0.0732 & \pm 5.91 \\
1.20 & 0.0760 & 0.0700 & \pm 7.89 \\
\hline
\end{tabular}

\section{Nozzle Section Effects and Discussion}

Simulations were carried out to compare the performance of annular multi-nozzle jet pumps with nozzle section of square, circular and triangle.

\subsection{Performance Comparison}

According to the simulation results, the pressure ratio curves and the efficiency curves of the jet pump are calculated by Equations (1) and (2), as shown in Figure 4.

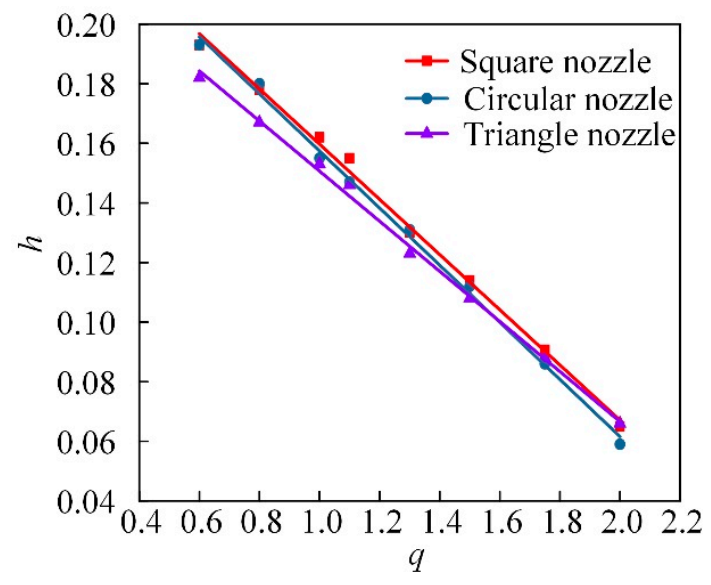

(a)

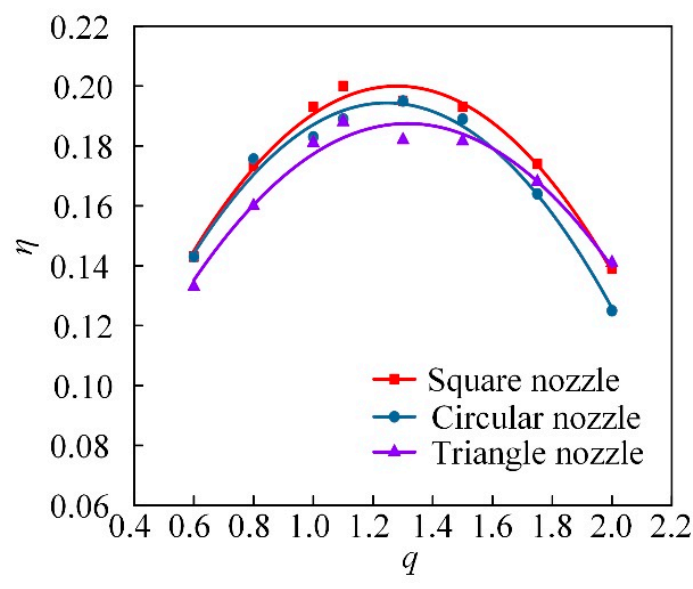

(b)

Figure 4. Pressure ratio curves and efficiency curves. (a) Pressure ratio; (b) Efficiency.

Figure 4a shows that the pressure ratio decreases linearly as the flow ratio increases. This is because the flow rate of the secondary fluid increases as the flow ratio increases. The pressure ratio of the pump with square nozzle is the highest one as a whole. The energy of the working fluid is transferred to the secondary fluid resulting in a decrease in the pressure at the jet pump exit. Figure $4 \mathrm{~b}$ shows that the efficiency increases firstly and then decreases with the increase of the flow ratio, and the efficiency of the pump with square nozzle is the highest in the given flow ratio range. The efficiency peak of the square nozzle pump is $20.1 \%$ at $q=1.1$, which is $3 \%$ higher than that of the circular nozzle pump and $4.1 \%$ higher than that of the triangular nozzle pump.

\subsection{Flow Field Analysis}

The distributions of the axial velocity of the jet pumps at $q=1.1$ are as shown in Figure 5. After the working fluid is ejected from the nozzle with a high velocity, it flows downstream along the wall of the suction chamber. The two fluids mixing basically completes at the end of the throat or the front of the diffuser and then further decelerates and boosts in the diffuser. From the suction chamber to the throat, the momentum of the high velocity jet is partially transferred to the second fluid by turbulent mixing. Comparing with circular and triangular nozzles, the square nozzle maintains high speed over a larger area and a long distance. The square multi-nozzle produces the minimized backflow (negative 
velocity) area, followed by the triangular nozzle, and the circular nozzle. In the XZ plane (through nozzle axis), velocity fields are symmetric about the axis for all three pumps. In the XY plane (between the two nozzles), the square nozzle and the triangular nozzle velocity fields are symmetrical about the axis. The fluid ejected from the circular nozzle deflects toward a side wall surface and flows along the wall surface, causing jet attaching effect.

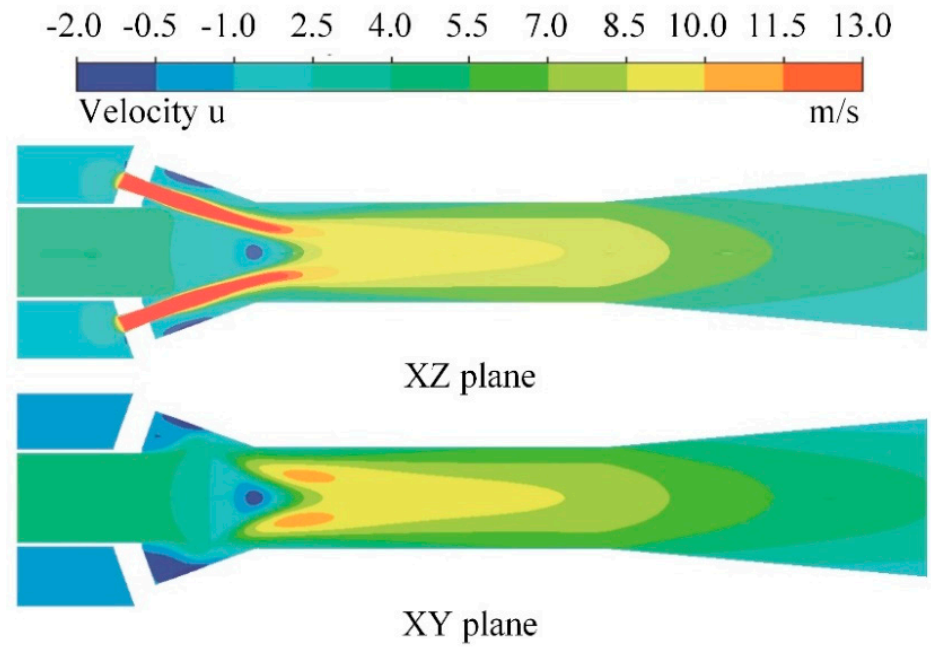

(a)
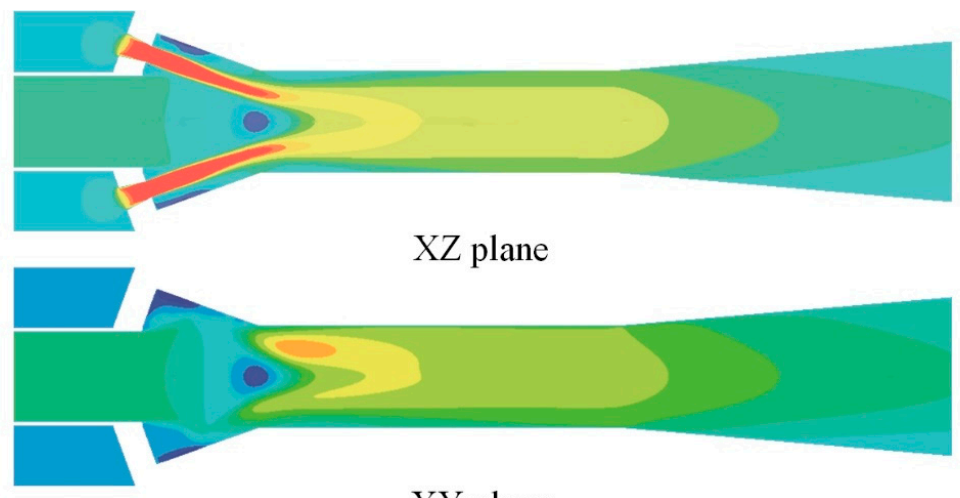

XY plane

(b)
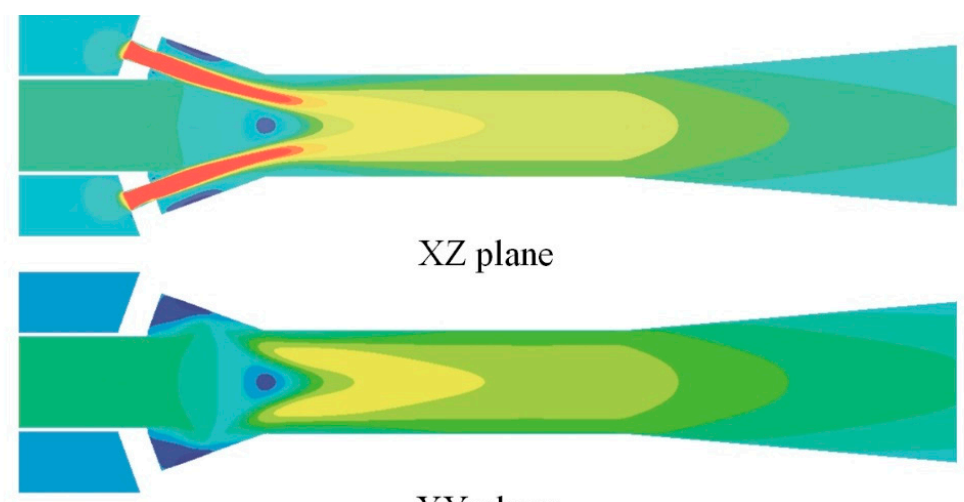

XY plane

(c)

Figure 5. The distribution of the axial velocity of the jet pump with different nozzle section geometries. (a) Square nozzle; (b) Circular nozzle; (c) Triangle nozzle. 
For a better observation, the velocity cloud and vector charts from the suction chamber to the throat inlet in the $\mathrm{XY}$ plane are enlarged as shown in Figure 6. The circular nozzle jet flow shown in Figure $6 \mathrm{~b}$ is disturbed in the suction chamber and the pressure loss on both sides is unbalanced. The main jet correspondingly deflects slightly. Therefore, the pressure on both sides of the main jet is unbalanced and the main jet is attached to the wall. The jet of the square or triangular nozzle is detached from the side walls as shown in Figure 6a,c.

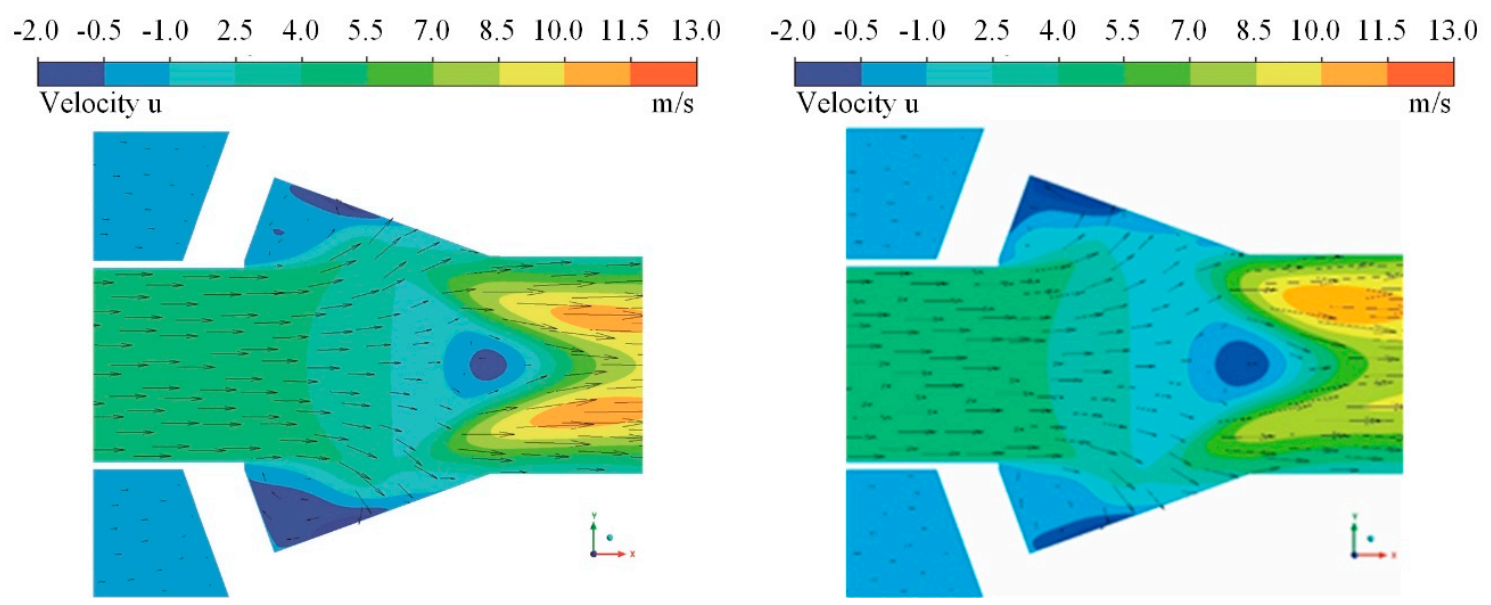

(a)

(b)

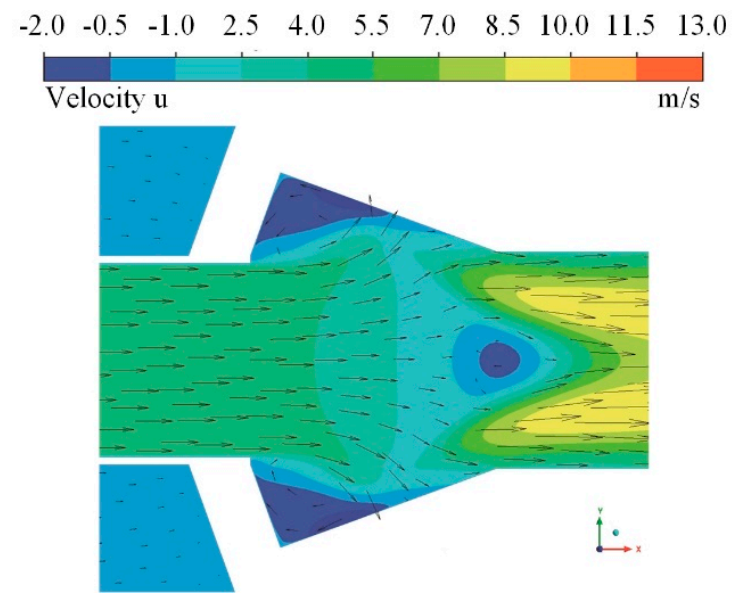

(c)

Figure 6. The velocity cloud and vector charts of square, circular and triangle nozzles. (a) Square nozzle; (b) Circular nozzle; (c) Triangle nozzle.

\subsection{Vortex Structure of the Confined Jet}

Vortex motion is a ubiquitous motion form in fluids. Turbulent motion could be regarded as the superposition of vortices with different scales, including a background flow field composed of a large number of random small vortices and large scale coherent vortex structures.

The internal flow of the jet pump belongs to confined coaxial jets with a main flow direction ( $x$ direction) in the flow field. The vortex can be decomposed into streamwise vortex and spanwise vortex. The direction of the streamwise vortex is parallel to the main flow direction. The direction of spanwise vortex is perpendicular to the main flow direction. In order to facilitate the analysis of the 
vortex structure of different models, dimensionless equations introduced by $\mathrm{Hu}$ [22] of the two kinds of vortex are shown below:

$$
\begin{gathered}
\Omega_{s}=\frac{D}{U_{0}}\left(\frac{\partial w}{\partial y}-\frac{\partial v}{\partial z}\right) \\
\Omega_{n}=\frac{D}{U_{0}} \sqrt{\left(\frac{\partial u}{\partial z}-\frac{\partial v}{\partial x}\right)^{2}+\left(\frac{\partial v}{\partial x}-\frac{\partial u}{\partial y}\right)^{2}}
\end{gathered}
$$

where $u, v$ and $w$ are the velocities in the $\mathrm{x}, \mathrm{y}$ and $\mathrm{z}$ directions, $\Omega_{S}$ is the streamwise vortex, $\Omega_{n}$ is the spanwise vortex, $D$ is the equivalent exit diameter of the nozzles, and $U_{0}$ is the working fluid velocity at the inlet.

\subsubsection{Streamwise Vortex Structure Analysis}

The distribution of the streamwise vortex in the cross-sections from the suction chamber to the throat along the $x$-axis with $q=1.1$ is as shown in Figure 7. The streamwise vortex structures mainly occur in the turbulent boundary layer. These counter-rotating streamwise vortices appear in pairs and correspond to the nozzle position and nozzle section geometry. The distribution of the streamwise vortex is stretched along the radial direction of the throat and vortex breakage occurs due to the influence of the adjacent vortex. The streamwise vortex is crucial to the entrainment effect of the jet and has a great relationship with the external characteristics of the device.

It can be seen from Figure 7 that the streamwise vortex diffusion and decay mainly occurs in the suction chamber. The perimeter of the square nozzle is greater than that of the circular nozzle, which increases the contact area and results in the greater scale of the streamwise vortex at the exit. With the mixing of the two fluids, the decay of the streamwise vortex of the square nozzle is kept uniform. The streamwise vortex structures of the circular nozzle are closer to the wall surface. This causes the attached flow to form a single-side expansion as shown in Figure $5 \mathrm{~b}$ and the friction loss increases. Although the perimeter of the triangular nozzle is longer than that of the circular nozzle, the streamwise vortex of the triangular nozzle is weaker due to the sharp angle of the nozzle section resulting in lower efficiency. Comparing these three models, the distribution and decay of the streamwise vortex has a great influence on the performance of the jet pump. The faster the flow vortex decays results in the higher the degree of mixing in the throat and the lower the friction loss, which is reflected by the external characteristics that the efficiency is higher.

The maximum streamwise vorticity values along the axial direction, $x$, from the suction chamber to the throat are shown in Figure 8. It can be seen that: in the suction chamber, the square nozzle streamwise vortices decay rapidly, and the circular nozzle and the triangular nozzle streamwise vortices are attenuated after the initial fluctuation; in the throat, especially of the square nozzle, the stream vortices decay gently as a whole and approach a lower value at the end of the throat where vortex structures are mainly caused by the pulsation of the flow. During the process, the maximum streamwise vorticity peak value of the square nozzle is $31 \%$ more than that of the circular nozzle and $39 \%$ more than that of the triangular nozzle.

In order to further study the entrainment effect of the streamwise vortex on the jet, the square nozzle was taken as an example to study the flow characteristics at the nozzle exit section. The distribution of the streamwise vortex and velocity vector at the exit section of the square nozzle are shown in Figure 9. Due to the rotation of streamwise vortices, the outer lateral secondary fluid is drawn from the edge of the vortex into the jet. At the same time, the high-velocity working fluid flows outwards under the influence of the streamwise vortex motion. The rotating of the streamwise vortex structures causes the convection between the working fluid and the secondary fluid resulting in the mixing effect. 
Streamwise vortex
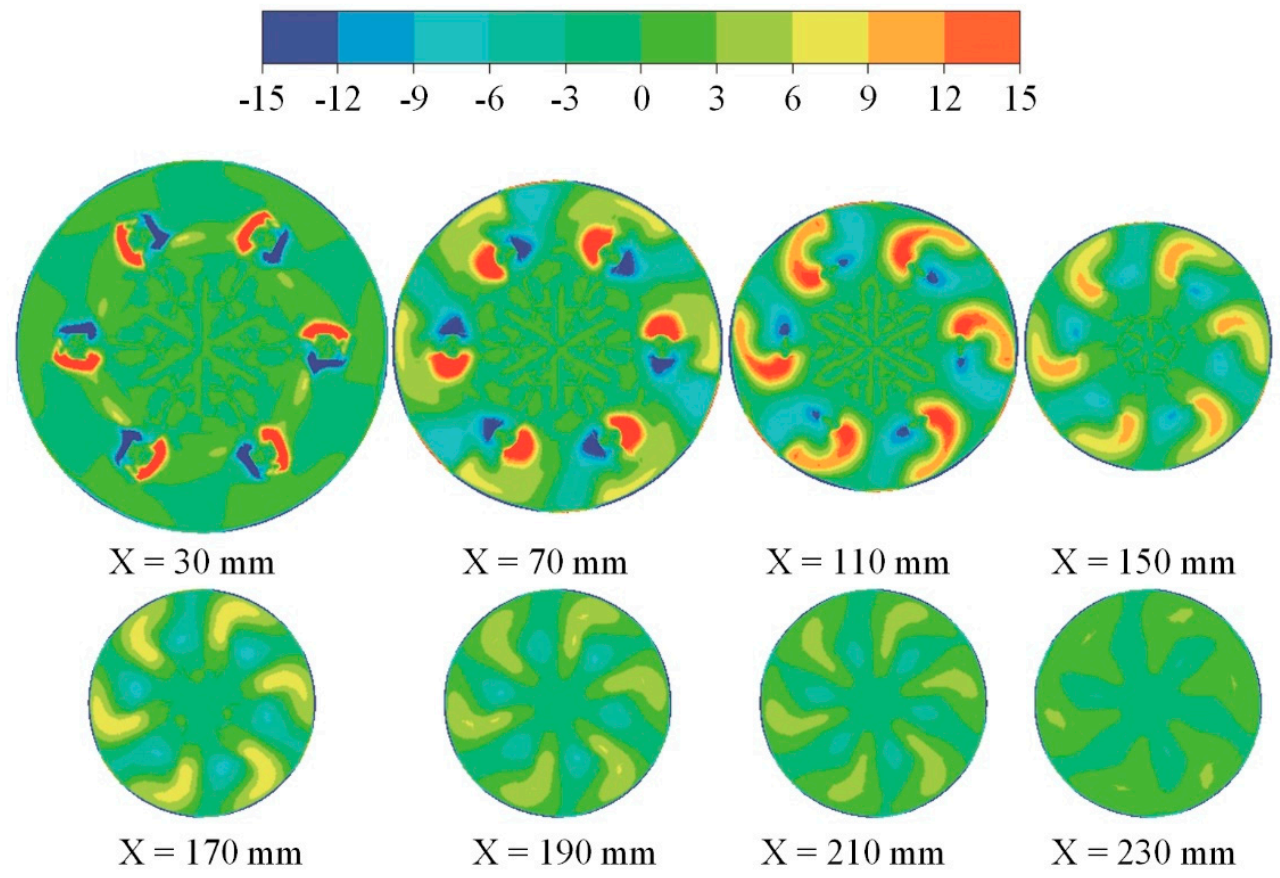

(a)

\section{Streamwise vortex}
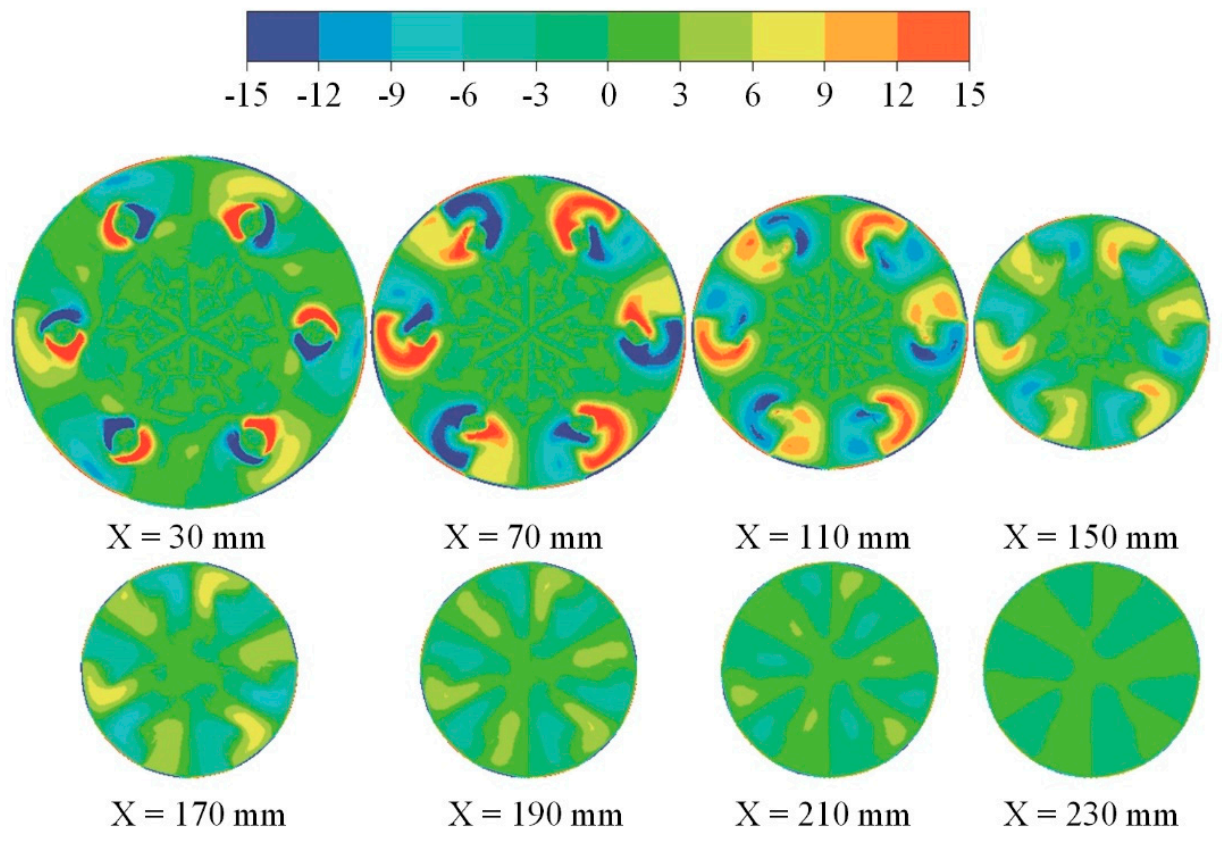

(b)

Figure 7. Cont. 
Streamwise vortex
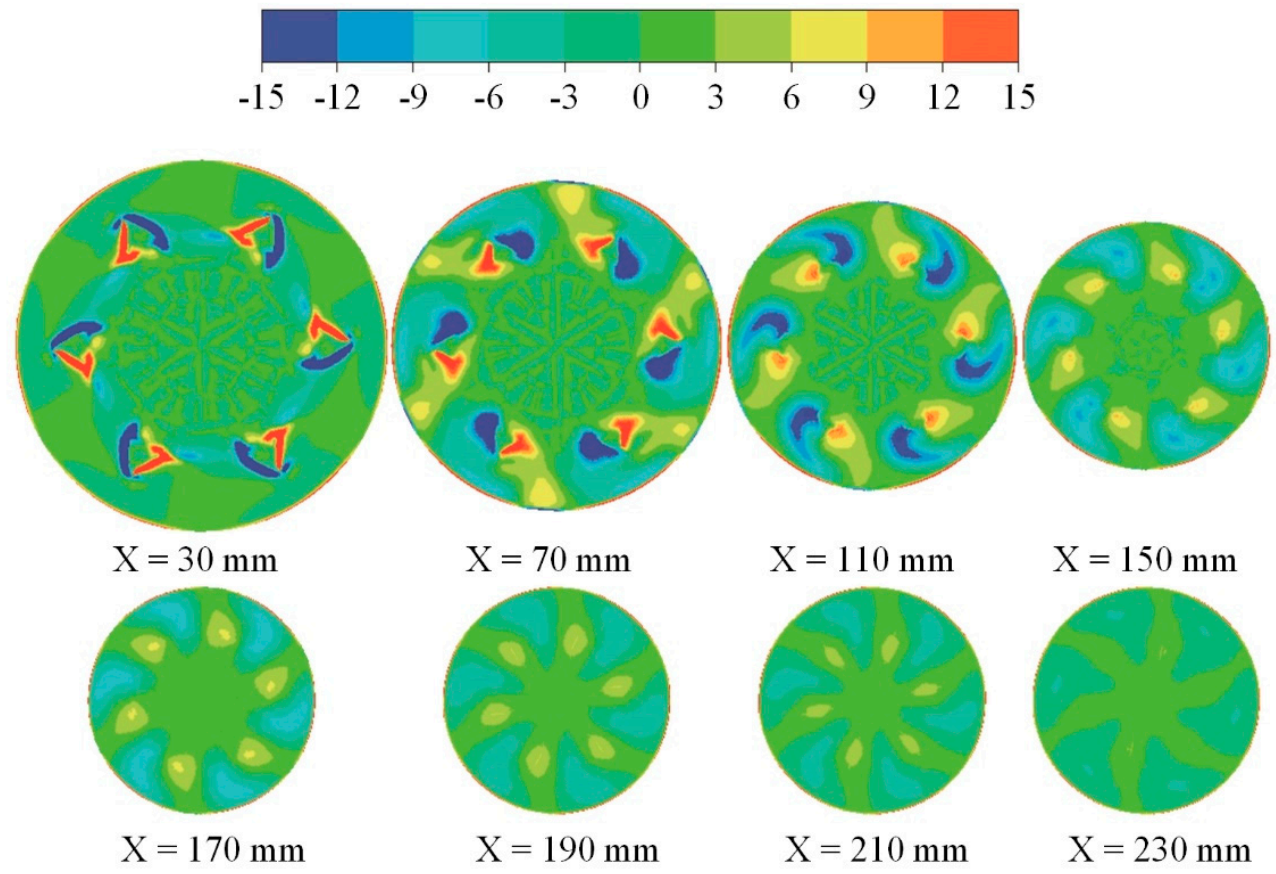

(c)

Figure 7. Streamwise vortex distribution. (a) Square nozzle; (b) Circular nozzle; (c) Triangle nozzle.

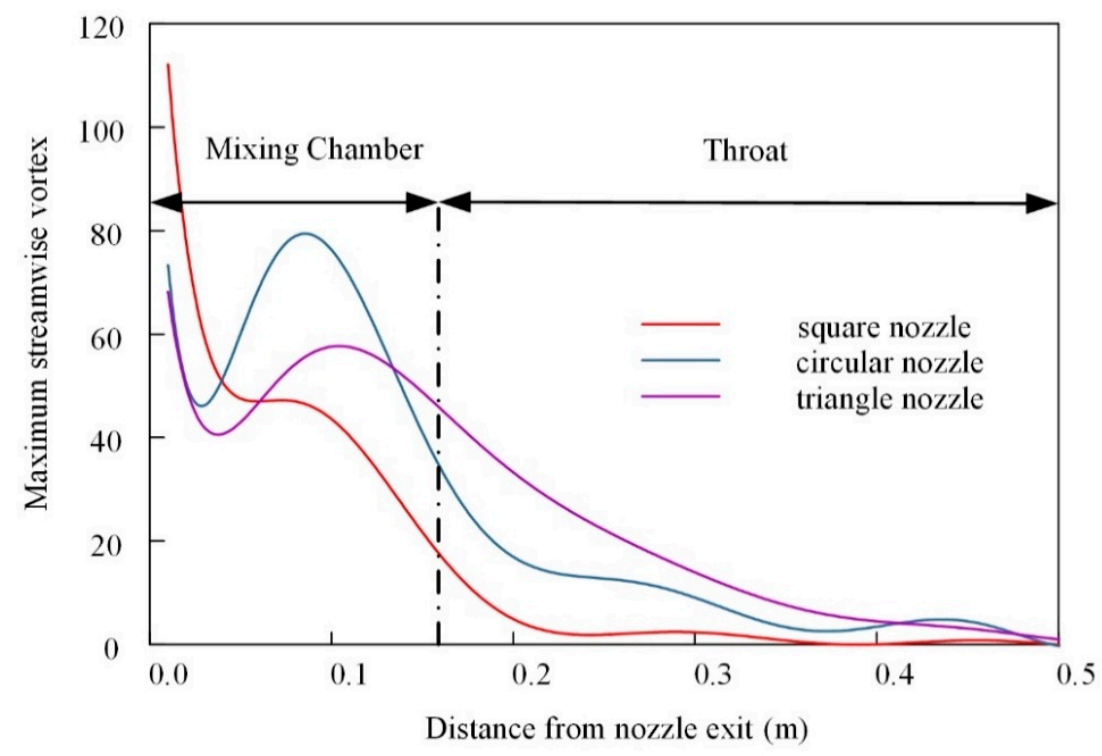

Figure 8. Decay of the maximum streamwise vortex.

\subsubsection{Spanwise Vortex Structure Analysis}

The spanwise vortex along the edge of the geometric structure is driven by the viscous shear force resulted from the velocity gradient of the working fluid and the secondary fluid. The spanwise vortex is perpendicular to the streamwise vortex and interacts with the streamwise vortex during the development of the flow. 
Streamwise vortex
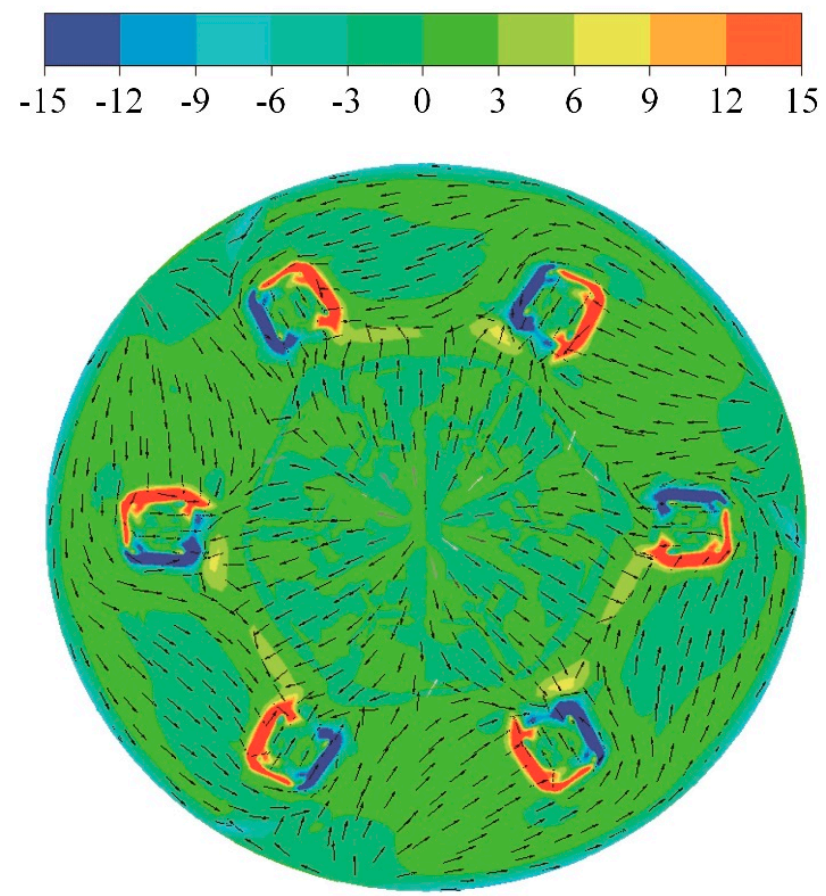

Figure 9. Streamwise vortex and velocity vector distribution at the exit of the square nozzle.

Figure 10 shows the distribution of the spanwise vortex in the cross-section from the suction chamber to the throat with $q=1.1$. Compared with the streamwise vortex, the strength of the spanwise vortex is significantly larger and decays more gently in the throat. In the front of the suction chamber, the vortex structure is dominated by the spanwise vortex in the initial stage of mixing. The distribution of the spanwise vortex is relatively regular, especially at the nozzle exit. The vortex distribution is similar to the shape of the nozzle exit constrained by the geometry of the nozzle. Due to the adhesion condition, the wall surface forms a certain area of the spanwise vortex structure. With the development of the flow, the vortex structure near the nozzle exit spreads toward the wall surface and decays. The vortex decay speed decreases gradually.

The maximum spanwise vorticity values along the axial direction $\mathrm{x}$ from the suction chamber to the throat are plotted in Figure 11. It can be seen that the maximum spanwise vorticity value decays rapidly in the suction chamber similar to the streamwise vortex. Then after the mixing of the two fluids in the downstream throat to a certain extent, this value still fluctuates with obvious ups and downs. During the process, the maximum spanwise vorticity peak value of the square nozzle is $19 \%$ less than that of the circular nozzle and $12 \%$ less than that of the triangular nozzle.

In order to further study the entrainment effect of the spanwise vortex on the jet, the square nozzle was taken as an example to study the flow characteristics in the XY plane. The distribution of the spanwise vortex and velocity vector in the $X Y$ plane are shown in Figure 12. Similar to streamwise vortex, the spanwise vortex can also cause the externally secondary fluid to be drawn into the jet from the edge of the vortex and the working fluid to flow outward to form a convection through the vortex rotation. This results in the mixing effect. However, as shown in Figure 12, owing to the spanwise vortex direction perpendicular to the mainstream direction of the jet pump, this entrainment effect will cause a recirculation zone in the longitudinal plane (such as the XY plane) and increase energy loss. Therefore, under the condition of constant vorticity, the lower the spanwise vortex strength is, the higher the device efficiency is. 
Spanwise vortex
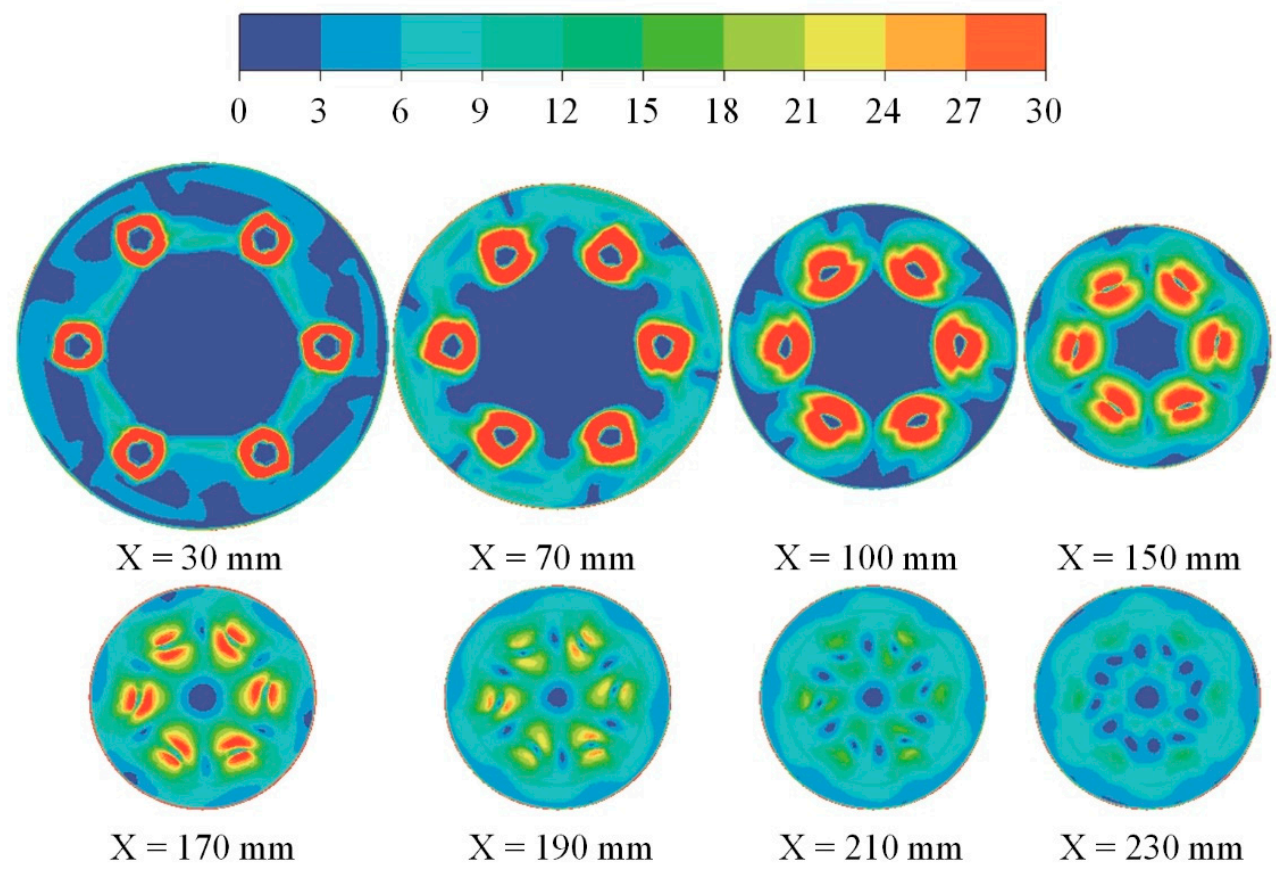

(a)

Spanwise vortex
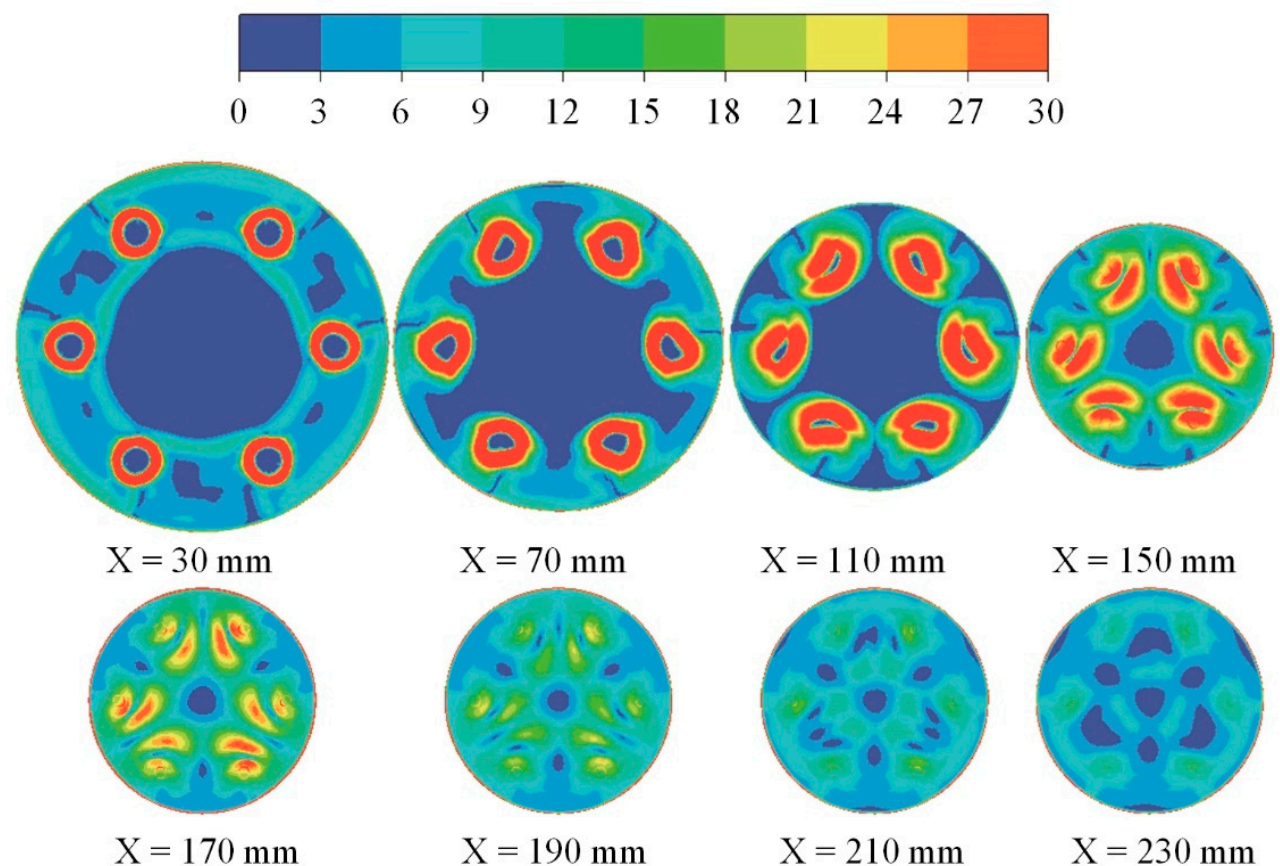

$\mathrm{X}=170 \mathrm{~mm}$

(b)

Figure 10. Cont. 


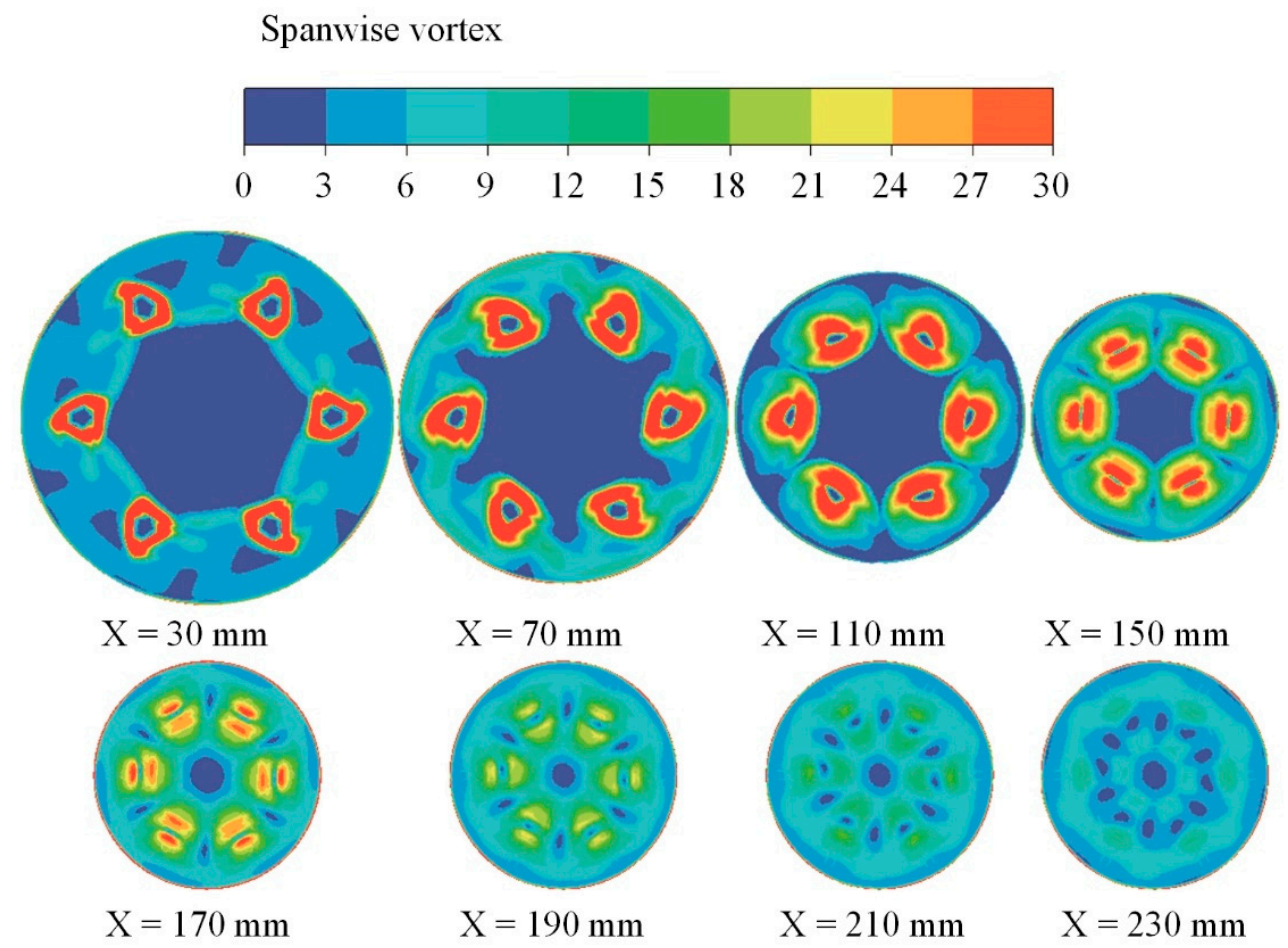

(c)

Figure 10. Spanwise vortex distribution. (a) Square nozzle; (b) Circular nozzle; (c) Triangle nozzle.

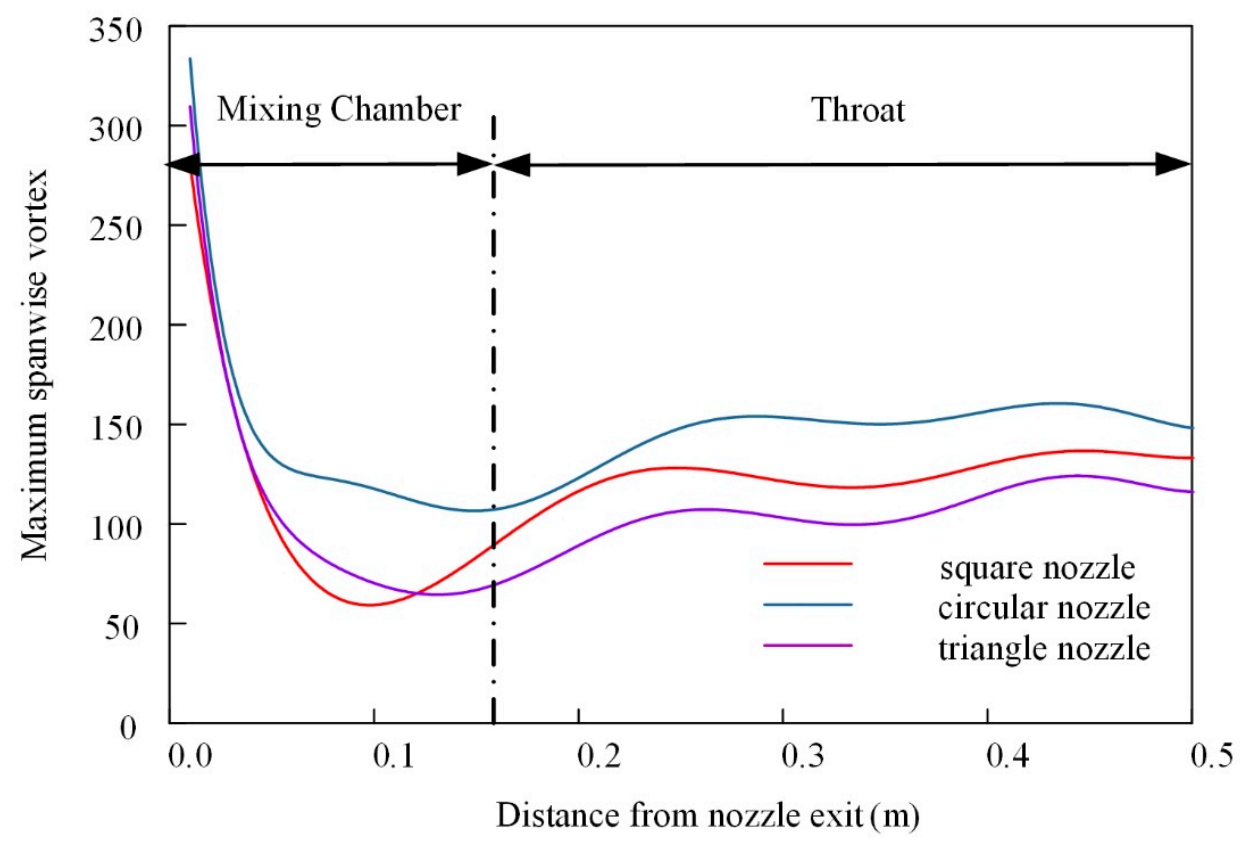

Figure 11. Decay of the maximum spanwise vorticity value.

According to the analysis results of Figures 8 and 11, it can be seen that the maximum streamwise vorticity value and the maximum spanwise vorticity value of the annular multi-nozzle jet pump have opposite laws, which conforms to the law of vorticity decomposition and reflects the influence of two vortex structures on the mixing effect. The streamwise vortex plays a major role in the mixing process. The stronger the streamwise vortex is and the faster the streamwise vortex decays, the higher the efficiency is. The spanwise vortex, which contributes little to the performance of the pump, fluctuates 
greatly and results in the recirculation. Therefore, the efficiency of the square nozzle is $3 \%$ higher than that of the circular nozzle and $4.1 \%$ higher than that of the triangular nozzle.

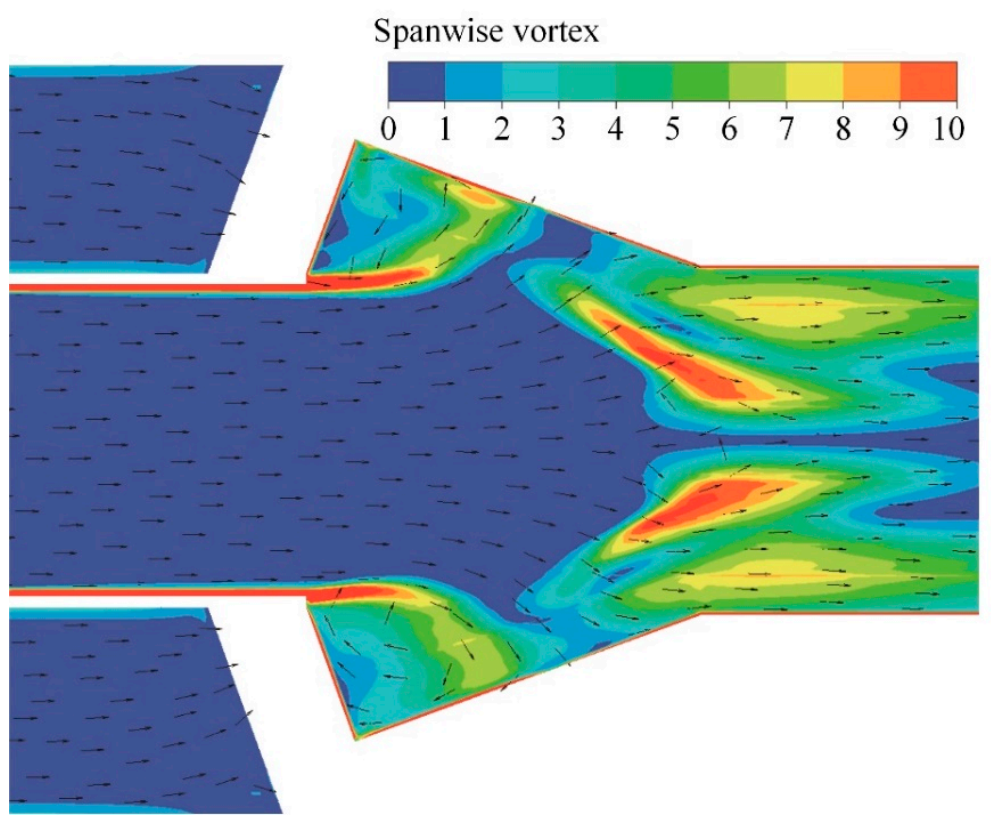

Figure 12. Spanwise vortex and velocity vector distribution in the XY plane.

\section{Conclusions}

This paper used the Realizable $k-\varepsilon$ model and the scalable wall function based on the finite volume method to numerically study the flow characteristic inside jet pumps with different nozzle structures and verified the simulation scheme with experimental data to ensure the reliability of the simulation results. Based on the simulation results and the introduction of vortex dynamics theory, the distribution of velocity, the spatial evolution laws of streamwise vortex and spanwise vortex, and the decay of the maximum vortex along the main flow direction in the cross-sections were studied. The following conclusions were obtained:

(1) The square nozzle peak efficiency is 3\% higher than that of the circular nozzle and $4.1 \%$ higher than that of the triangular nozzle;

(2) Compared with the conventional circular nozzle, the recirculation area and the friction loss are reduced by the non-circular nozzles and the mixing effect is improved;

(3) The streamwise vortex plays a major role in the mixing process and decays to an extremely small value at the end of the throat after decaying rapidly in the suction chamber. Therefore, the greater the streamwise vortex strength is, the higher the device efficiency is.

(4) Compared with the streamwise vortex, the strength of the spanwise vortex is stronger and the overall change is relatively lower. The spanwise vortex is a vortex component that is perpendicular to the main flow direction. Although it also contributes to the mixing effect, it causes a backflow phenomenon and increases friction loss.

(5) During the process, the maximum streamwise vorticity peak value of the square nozzle is $31 \%$ more than that of the circular nozzle and 39\% more than that of the triangular nozzle; the maximum spanwise vorticity peak value of the square nozzle is $19 \%$ less than that of the circular nozzle and $12 \%$ less than that of the triangular nozzle.

Author Contributions: Formal analysis, K.X. and G.W.; Methodology, K.X.; Writing-original draft preparation, K.X., and G.W.; Writing-review and editing, L.W., F.Y., W.S. and X.C.; Validation, L.W. and X.W.; Supervision L.W.; Funding acquisition, G.W. and F.Y. All authors have read and agreed to the published version of the manuscript. 
Funding: This research was funded by National Key Research and Development Project (Grant No. 2018YFF01012903), National Natural Science Foundation of China (Grant No. 51779059, 51409058, 61633009), China Postdoctoral Science Foundation (Grant No. 2018M630343), Science and Technology on Underwater Vehicle Laboratory (Grant No. 614221503041701), Science Foundation of Heilongjiang Institue of Technogly for Doctor Scholars (Grant No. 2015QJ04) and Fundamental Research Funds for the Central Universities (Grant No. 3072019CF0705).

Acknowledgments: The authors gratefully acknowledge the financial support from National Key Research and Development Project (Grant No. 2018YFF01012903), National Natural Science Foundation of China (Grant No. 51779059, 51409058, 61633009), China Postdoctoral Science Foundation (Grant No. 2018M630343), Science Foundation of Heilongjiang Institue of Technogly for Doctor Scholars (Grant No. 2015QJ04) and Fundamental Research Funds for the Central Universities (Grant No. 3072019CF0705).

Conflicts of Interest: The authors declare no conflict of interest.

\section{References}

1. Meakhail, T.; Teaima, I. Experimental and numerical studies of the effect of area ratio and driving pressure on the performance of water and slurry jet pumps. Proc. Inst. Mech. Eng. Part C J. Mech. Eng. Sci. 2012, 226, 2250-2266. [CrossRef]

2. Long, X.; Xu, M.; Wang, J.; Zou, J.; Bin, J. An experimental study of cavitation damage on tissue of Carassius auratus in a jet fish pump. Ocean Eng. 2019, 174, 43-50. [CrossRef]

3. Yapıc1, R.; Aldas, K. Optimization of water jet pumps using numerical simulation. Proc. Inst. Mech. Eng. Part A J. Power Energy 2013, 227, 438-449. [CrossRef]

4. Yang, X.; Long, X.; Yao, X. Numerical investigation on the mixing process in a steam ejector with different nozzle structures. Int. J. Therm. Sci. 2012, 56, 95-106. [CrossRef]

5. Deng, X.; Dong, J.; Wang, Z.; Tu, J. Numerical analysis of an annular water-air jet pump with self-induced oscillation mixing chamber. J. Comput. Multiph. Flows 2017, 9, 47-53. [CrossRef]

6. Sheha, A.A.A.; Nasr, M.; Hosien, M.A.; Wahba, E.M. Computational and Experimental Study on the Water-Jet Pump Performance. J. Appl. Fluid Mech. 2018, 11, 1013-1020. [CrossRef]

7. Sun, Y.; Chen, G.; Yin, S. The effect of inlet convergence angle on flow field and performance inside the jet pump. In Proceedings of the Asia-Pacific Power and Energy Engineering Conference, Wuhan, China, 25-28 March 2011. [CrossRef]

8. Fan, J.; Eves, J.; Thompson, H.M.; Toropov, V.V.; Kapur, N.; Copley, D.; Mincher, A. Computational fluid dynamic analysis and design optimization of jet pumps. Comput. Fluids 2011, 46, 212-217. [CrossRef]

9. Zou, C.H.; Li, H.; Tang, P.; Xu, D.H. Effect of structural forms on the performance of a jet pump for a deep well jet pump. In Proceedings of the International Conference on Computational Methods and Experimental Measurements 17th, Opatija, Croatia, 5-7 May 2015. [CrossRef]

10. Zhu, X.; Wang, D.; Xu, C.; Zhu, Y.; Zhou, W.; He, F. Structure influence on jet pump operating limits. Chem. Eng. Sci. 2018, 192, 143-160. [CrossRef]

11. Lyu, Q.; Xiao, Z.; Zeng, Q.; Xiao, L.; Long, X. Implementation of design of experiment for structural optimization of annular jet pumps. J. Mech. Sci. Technol. 2016, 30, 585-592. [CrossRef]

12. Duan, X.; Sun, $X$. The Experimental study on compositional parameters of the annular multinozzle jet pump. Explor. Eng. 1999, 6, 17-20. [CrossRef]

13. Long, X.P.; Yang, X.L.; Yao, X. Flow simulation and vortex structure analysis of multi-nozzle jet pumps. J. Drain. Irrig. Mach. Eng. 2012, 30, 136-140. [CrossRef]

14. Yang, X.; Long, X.; Xiao, L.; Lu, Q. Influence of different turbulence models on simulation of internal flow field of jet pump. J. Drain. Irrig. Mach. Eng. 2013, 31, 98-102. [CrossRef]

15. Long, X.; Han, N.; Chen, Q. Influence of nozzle exit tip thickness on the performance and flow field of jet pump. J. Mech. Sci. Technol. 2008, 22, 1959-1965. [CrossRef]

16. Yamazaki, Y.; Yamazaki, A.; Narabayashi, T.; Suzuki, J.; Shakouchi, T. Studies on Mixing Process and Performance Improvement of Jet Pumps. J. Fluid Sci. Technol. 2007, 2, 238-247. [CrossRef]

17. Guillaume, D.W.; Judge, T.A. Improving the efficiency of a jet pump using an elliptical nozzle. Rev. Sci. Instrum. 1999, 70, 4727-4729. [CrossRef]

18. Mallela, R.; Chatterjee, D. Numerical investigation of the effect of geometry on the performance of a jet pump. Proc. Inst. Mech. Eng. Part C J. Mech. Eng. Sci. 2011, 225, 1614-1625. [CrossRef] 
19. Kwon, O.B.; Kim, M.K.; Kwon, H.C.; Bae, D.S. Two-dimensional Numerical Simulations on the Performance of an Annular Jet Pump. J. Vis. 2002, 5, 21-28. [CrossRef]

20. Narabayashi, T.; Yamazaki, Y.; Kobayashi, H.; Shakouchi, T. Flow Analysis for Single and Multi-Nozzle Jet Pump. JSME Int. J. Ser. B Fluids Therm. Eng. 2006, 49, 933-940. [CrossRef]

21. Shih, T.; Liou, W.; Shabbir, A.; Yang, Z.; Zhu, J. A new $k-\varepsilon$ eddy viscosity model for high reynolds number turbulent flows. Comput. Fluids 1995, 24, 227-238. [CrossRef]

22. Hu, H.; Saga, T.; Kobayashi, T.; Taniguchi, N. Mixing process in a lobed jet flow. Aiaa J. 2002, 40, 1339-1345. [CrossRef]

(C) 2020 by the authors. Licensee MDPI, Basel, Switzerland. This article is an open access article distributed under the terms and conditions of the Creative Commons Attribution (CC BY) license (http://creativecommons.org/licenses/by/4.0/). 